\title{
ВмJ Global Health Unmasking power as foundational to research on sexual and reproductive health and rights
}

\author{
Marta Schaaf (D) , ${ }^{1}$ Anuj Kapilashrami, ${ }^{2}$ Asha George (D) , ${ }^{3}$ Avni Amin, ${ }^{1}$ Soo Downe, ${ }^{4}$ \\ Victoria Boydell, ${ }^{5}$ Goleen Samari, ${ }^{6}$ Ana Lorena Ruano, ${ }^{7,8}$ Priya Nanda, ${ }^{9}$ \\ Rajat Khosla ${ }^{1}$
}

To cite: Schaaf M, Kapilashrami A, George A, et al. Unmasking power as foundational to research on sexual and reproductive health and rights. BMJ Global Health 2021;6:e005482. doi:10.1136/ bmjgh-2021-005482

Received 22 February 2021 Revised 13 March 2021 Accepted 15 March 2021
Check for updates

(c) Author(s) (or their employer(s)) 2021. Re-use permitted under CC BY-NC. No commercial re-use. See rights and permissions. Published by BMJ.

For numbered affiliations see end of article.

Correspondence to

Dr Marta Schaaf;

martaschaafconsult@gmail.com
Relations of power are intrinsic to the social determinants of sexual and reproductive health (SRH); they influence the content, quality and outcomes of SRH care; and they shape the negotiation and realisation of sexual and reproductive health and rights (SRHR) more broadly. Power dynamics pervade how SRHR is understood, studied and acted on, in ways that are distinct from other health issues. ${ }^{1}$ For example, the deeply held personal beliefs about women's sexuality and childbearing, cultural mores regarding adolescent sexuality and state goals related to fertility all mark SRHR as a sphere with distinct and deeply contested power dynamics.

Unmasking power as a central element in SRHR research is therefore crucial to developing a research agenda that can produce knowledge to transform hierarchies of power and advance SRHR. ${ }^{2}$ For example, key studies on violence against women and HIV that included explicit measures of power broke new ground by assessing how multilevel programmes impacted power relations and SRH outcomes, thus elucidating the importance of power relations, the factors that shape power relations and how these relations can be changed..$^{3-5}$ In this Commentary, we summarise key ways power has been understood, defined and operationalised in SRHR research. We propose areas where further theoretical and empirical work and improved research processes could better interrogate power, yielding insights that can help transform policies, programmes and services.

Though few would disagree with the notion that 'power matters', there are many different approaches to describing and addressing power in SRHR-related research. These approaches reflect distinct academic disciplines and points of view (eg, practitioners, researcher, policymaker, activist). In
Summary box

The current extensive body of research on power and sexual and reproductive health and rights (SRHR) assesses power at various levels of analysis, from the micro to the meso and the macro, and their interstices.

- Some research describes expressions of power and how these affect SRHR, while other research seeks to identify how power dynamics shaping SRHR can be shifted.

- We propose areas where further theoretical and empirical work could better interrogate power, strengthening the evidence base for action.

- Areas for further research include researching the role of 'hidden' flows of power in shaping global SRHR agendas; examining the relationship between macrolevel flows of power and communities' SRHR care experiences; deepening insight into the exercise of power by patients and service users, and among providers at the front lines of the healthcare system; and embedded research and evaluation on civil societies' and the government's role in larger social movements.

- These priorities for research content have implications for research processes. Most importantly,research agendas should better reflect the priorities of people most affectedby SRH injustice, and thegrassroots groups that work in these communities.

this Commentary, we use a working conceptualisation of power that draws on much of the foundational thinking on power in the social sciences and its application to health policy and systems research. Power shapes individual perceptions and actions; social relations; and economic, legal and political structures. It is expressed both explicitly and implicitly through ideas, norms, capital and the use of force. Power is diffuse, as it both flows from and reinforces social, political and other hierarchies. ${ }^{6-9}$ 


\section{HOW POWER HAS BEEN OPERATIONALISED IN SRHR RESEARCH}

Academicians study power at various levels of analysis, from the micro to the meso and the macro, and their interstices. Some research describes expressions of power and how these affect SRHR, while other research seeks to identify how power dynamics shaping SRHR can be shifted.

There is a rich and varied tradition of descriptive research related to power and SRHR in the social sciences.

For example, demographers and other social scientists examine associations between measures of individual (usually women's) empowerment, and SRH service use or health outcomes. ${ }^{10}{ }^{11}$ Some health system researchers focus on institutions and policies (meso), and interpersonal relationships (micro) to study how the exercise of discursive and material power from 'the top' interacts with the preferences and decision space of those tasked with implementing policy. ${ }^{12}$ This research elucidates the exercise and contestation of power in processes of agenda setting and policy making ${ }^{13}{ }^{14}$; the implementation, negotiation and subversion of health strategies and policies ${ }^{15-17}$ and the ways that sociocultural norms are enacted in institutions. An example of the latter is the mistreatment faced by many women during labour. ${ }^{18}$ Social scientists and increasingly social epidemiologists describe how the interactions of social divisions, such as gender, caste, religion, immigration status, race and disability, create inequalities in the distribution of determinants and outcomes of SRH. ${ }^{19-21}$ A rich tradition in political science, sociology, economics and anthropology illustrates how the structures of political, economic and social systems shape the social determinants of health and human rights, including SRHR. ${ }^{22}$

Research to assess if and how power dynamics can be shifted to improve SRHR is more limited than the descriptive and exploratory work on power, but the existing research provides important insights. Among other areas, it has included evaluations of interventions to address violence against women ${ }^{23}$; case studies of social accountability projects that facilitate collective action to claim rights and entitlements ${ }^{24-26}$; or programmes to foster individual and/or community empowerment. ${ }^{5}$

Building on this past work to expand the application of the concept of power more centrally, explicitly and systematically in SRHR research will broaden and strengthen the evidence base for action. Fully unmasking power also requires that researchers consider how power dynamics in their own institutions and lives shape whether and how they prioritise constructs of power in their research. We draw on Östlin $e t a l$ s delineation of research content and processes to propose example areas of research content where deeper engagement with power could uncover key determinants and barriers to realising SRHR. ${ }^{27} \mathrm{We}$ suggest how research processes can be adapted to further develop the research agenda on power and SRHR. Moreover, research agendas reflect institutional power and the biases of the individuals working therein, so exploring new areas and ways of doing research will require changes in research funding, operations, publishing and dissemination.

We recognise that SRHR is a fast-evolving field with committed researchers and practitioners at all levels; we offer our thoughts as part of broader dialogues on researching power, decolonising global health; and researching and overcoming the neocolonial, racist, coercive and paternalistic basis of much of the early work on reproductive health. ${ }^{28} 29$

\section{RESEARCHING THE ROLE OF POWER IN SHAPING GLOBAL SRHR AGENDAS}

SRHR agendas in global health policy institutions are often negotiated political outcomes where the power is implicit. In the last two decades, a fair amount of literature has documented the role of conservative actors in influencing United Nations outcomes in relation to SRHR (eg, ref 30 31). However, there has been less documentation of how 'hidden' flows of power-such as discursive power to set the parameters of the discussion-shape what health goals, which population groups and what framings are reflected in other multilateral SRHR agendas, including, for example, FP2020 and the Global Financing Facility. Relevant questions include if and how the commercial determinants of SRH acknowledged. How is abortion presented? How does the notion of the victim subject ${ }^{32}$ or vague formulations of notions of vulnerability ${ }^{33}$ shape which groups are prioritised in policies? Building on the rich history of research on agenda setting in global health, research on who has the power of money, the power of voice and strategic alliances, the power of knowledge and the power of having a seat at the decision-making table can contribute to improving how SRHR agendas are negotiated. Such research can better inform SRHR advocacy.

\section{EXAMINING THE RELATIONSHIP BETWEEN MACROLEVEL FLOWS OF POWER AND COMMUNITIES' SRHR CARE EXPERIENCES}

Work done by feminist and other social justice movements as well as research on social determinants of health has pointed to the social, economic, political and, increasingly, commercial power structures that are drivers or determinants of SRH outcomes, accessibility and quality of services. These determinants are influenced by hierarchical and patriarchal government institutions and include, for example, the (ill)legality of abortion, the role of austerity policies in cutting funding for reproductive and maternal health, and links between climate change and reproductive injustice. ${ }^{34-38}$

To deepen our understanding of the impact of macrolevel flows of power, it would be helpful to complement the focus on determinants and further explicate the sites and the expressions of power at multiple levels-global, national, subnational and at the front lines of healthcare delivery. The resultant research could 
illustrate the actual impact of decisions and processes that occur far from the ground, such as whether and how they affect the quality of care and the cost of services, the availability of different types of contraception and the extent to which the private sector is predatory. This research can provide needed insight into how national policies can shape health service provision.

\section{DEEPENING INSIGHT INTO THE EXERCISE OF POWER BY PATIENTS AND SERVICE USERS, AND AMONG PROVIDERS AT THE FRONT LINES OF THE HEALTHCARE SYSTEM}

Research and pilot programmes within the burgeoning field of respectful maternity care revealed the ways that poor and historically oppressed people are treated or abused in maternity care. At the same time, some of this research has shown how providers who perpetrate mistreatment of women are themselves navigating gendered, hierarchical and potentially punitive workplace power dynamics. ${ }^{18}$

We need more detailed emic, front-line accounts of patient, provider and district-level phenomena that are consequential to communities, such as racism and casteism in the delivery of contraceptive care, health provider demands for informal payments for maternity care, coercion in the provision of contraception, provider bias and reluctance to provide legal abortions, the ways that intersecting identities shape the patient experience, and district-level failure (or inability) to spend funds and how this affects historically oppressed groups. These expressions of power are related to wider social and health system dynamics, and they are also consequential acts that shape experiences of care. Deepening our understanding of the content and context of these interactions would inform the development of programmes and that are sensitive to power dynamics and that can address them.

\section{EMBEDDED RESEARCH AND EVALUATION ON CIVIL SOCIETIES' AND THE GOVERNMENT'S ROLE IN LARGER SOCIAL MOVEMENTS}

Civil society efforts, particularly in health, are too often 'projectized', with donors funding short-term programmes and then asking for research and evaluation that assesses whether these programmes produce improvements in SRH coverage and utilisation indicators. ${ }^{39}$ Global health researchers accustomed to the biomedical paradigm logic of precomparisons/postcomparisons and health coverage outcomes may reinforce this emphasis. This approach risks ignoring and devaluing adaptive 'long game' approaches to changing the narrative about important power relations shaping SRHR, such as gender norms, food security, and robust, publicly funded health systems. Long-term, embedded research and learning about when and how these goals are met could provide important lessons for programme strategists and donors. This can help illuminate more effective programme and funding strategies.

\section{REFLECTING PRIORITIES OF PEOPLE AFFECTED BY SRH}

\section{INJUSTICE}

These priorities for research content have implications for research processes. Most importantly, research agendas should better reflect the priorities of people most affected by SRH injustice, and the grass-roots groups that work in these communities. As championed by the Black-led movement for reproductive justice in the USA, fulfilling community-driven research agendas requires privileging different forms of knowledge and research. It also requires conscious efforts to give power to the communities and groups that are typically the 'subjects' of research. ${ }^{40}$ Bottom-up agenda setting can help produce research that suggests new ways to reach widely shared goals, such as access to quality maternity care. It requires a conscious and proactive approach to engaging oppressed communities in agenda shaping by creating opportunities for a level playing field with researchers, recognising that social norms, economic barriers and historic exclusion pose extra barriers to participation.

Moreover, the outcomes of interest assessed in many intervention studies in SRHR reflect the norms and interests of researchers. These norms tend to conceptualise SRH in the light of what health professionals have interest in and control over: pathology and treatment, with outcomes, as a consequence, focused on short-term morbidity or mortality. The people whose SRH experiences are being researched might have very different concerns. The movements led by HIV activists to support treatment literacy and authentic community engagement in clinical trials offer some concrete ways to share biomedical information and research decision-making power. ${ }^{41}$ Creating socially grounded and community-based quantitative measures of power and empowerment for SRHR is another way to ensure community engagement and relevancy of the research agenda. ${ }^{11}$ Working closely with communities can aid the development of locally resonant research agendas, and joint development of action agendas arising from the research, ultimately linking local voices with action and policy development.

\section{CONCLUSION}

Our list of illustrative areas for deeper research could certainly be expanded, but our key message is that power is valuable as a unifying construct insofar as it helps to turn our attention to the drivers (the causes of causes) that matter most. For example, the difference between work that is gender neutral and work that is gender transformative is whether or not it influences the systems that give rise to gender hierarchies-power differentials. We must expect the same from our research. Researchers can do this while working from a number of different disciplines, applying diverse theories and employing diverse methods. Addressing power does not necessarily require formulating research questions that are exclusively and explicitly about power, but it does mean considering how power influences every element of the research 
endeavour. In so doing, we can enhance the rigour, relevance and ramifications of research on SRHR.

\section{Author affiliations}

${ }^{1}$ Development and Research Training in Human Reproduction (HRP), Department of Sexual and Reproductive Health and Research, World Health Organization, Geneve, Switzerland

${ }^{2}$ School of Health and Social Care, University of Essex, Colchester, UK

${ }^{3}$ School of Public Health, University of the Western Cape Faculty of Community and Health Sciences, Cape Town, Western Province, South Africa

${ }^{4}$ School of Community Health and Midwifery, University of Central Lancashire,

Preston, UK

${ }^{5}$ Global Health Centre, Geneva Graduate Institute, Geneva, Switzerland

${ }^{6}$ Heilbrunn Department of Population and Family Health, Columbia University

Mailman School of Public Health, New York, New York, USA

${ }^{7}$ Centre for International Health, University of Bergen, Bergen, Norway

${ }^{8}$ Center for the Study of Equity and Governance in Health Systems (CEGSS), Guatemala City, Guatemala

${ }^{9}$ Bill and Melinda Gates Foundation India, New Delhi, Delhi, India

Twitter Marta Schaaf @martaschaaf and Asha George @ashageorge72

Acknowledgements Kerry Scott was involved in early discussions regarding this manuscript, and kindly provided comments on early versions.

Contributors MS and RK conceived the manuscript. MS led the drafting of the paper. AK, AG, AA, SD, VB, GS, LR, PN and RK all drafted some text, and read and commented on several versions of the paper. All authors read and approved the final manuscript.

Funding This manuscript was developed with support from the UNDP-UNFPAUNICEF-WHO-World Bank Special Programme of Research, Development and Research Training in Human Reproduction (HRP Research), a cosponsored programme executed by WHO. Asha George is supported by the South African Research Chair's Initiative of the Department of Science and Technology and National Research Foundation of South Africa (Grant No 82769) and the South African Medical Research Council. Any opinion, finding and conclusion or recommendation expressed in this material is that of the author and the NRF does not accept any liability in this regard.

Competing interests None declared.

Patient consent for publication Not required.

Provenance and peer review Not commissioned; internally peer reviewed.

Data availability statement There are no data in this work.

Open access This is an open access article distributed in accordance with the Creative Commons Attribution Non Commercial (CC BY-NC 4.0) license, which permits others to distribute, remix, adapt, build upon this work non-commercially, and license their derivative works on different terms, provided the original work is properly cited, appropriate credit is given, any changes made indicated, and the use is non-commercial. See: http://creativecommons.org/licenses/by-nc/4.0/.

\section{ORCID iDs}

Marta Schaaf http://orcid.org/0000-0002-7616-5966

Asha George http://orcid.org/0000-0002-5968-1424

\section{REFERENCES}

1 Gilmore K, Khosla R. Sex, sexuality, and sexual and reproductive health: the role of human rights. Open Global Rights, 2020. Available: https://www.openglobalrights.org/the-role-of-humanrights-in-sexuality-and-sexual-and-reproductive-health/

2 Schaaf M, Topp S, Sriram V. Social science researchers' musings on power and health systems, 2018. Available: http://www.internationa Ihealthpolicies.org/social-science-researchers-musings-on-powerand-health-systems

3 Abramsky T, Devries K, Kiss L, et al. Findings from the Sasa! study: a cluster randomized controlled trial to assess the impact of a community mobilization intervention to prevent violence against women and reduce HIV risk in Kampala, Uganda. BMC Med 2014;12:1-7

4 Taft A, Small R. Preventing and reducing violence against women: innovation in community-level studies. BMC Med 2014;12:1-3.
5 Robinson JL, Narasimhan M, Amin A, et al. Interventions to address unequal gender and power relations and improve self-efficacy and empowerment for sexual and reproductive health decisionmaking for women living with HIV: a systematic review. PLoS One 2017;12:e0180699.

6 Sriram V, Topp SM, Schaaf M, et al. 10 best resources on power in health policy and systems in low- and middle-income countries. Health Policy Plan 2018;33:611-21.

7 Sen G, lyer A, Chattopadhyay S, et al. When accountability meets power: realizing sexual and reproductive health and rights. Int $J$ Equity Health 2020;19:1-11.

8 Erasmus E, Gilson L. How to start thinking about investigating power in the organizational settings of policy implementation. Health Policy Plan 2008:23:361-8.

9 Shawar YR, Ruger JP. approaches to studying the role of power. In: The politics of global health inequalities. Oxford, UK: The Oxford Handbook of Global Health Politics, 2019: 59-89.

10 Samari G. Education and fertility in Egypt: Mediation by women's empowerment. SSM Popul Health 2019;1:100488.

11 Upadhyay UD, Dworkin SL, Weitz TA, et al. Development and validation of a reproductive autonomy scale. Stud Fam Plann 2014:45:19-41.

12 Kapilashrami A, Baru R. Global Health governance and commercialisation of public health in India: Actors, institutions and the dialectics of global and local. In: Kapilashrami A, Baru R, eds. Health governance and commercialisation of public health in India. Abingdon: Routledge, 2019: 1.

13 Béhague DP, Storeng KT. Collapsing the vertical-horizontal divide: an ethnographic study of evidence-based policymaking in maternal health. Am J Public Health 2018;98:644-9.

14 Shiffman J. Generating political priority for maternal mortality reduction in 5 developing countries. Am J Public Health 2007;97:796-803.

15 de Sardan JPO, Diarra A, Moha M. Travelling models and the challenge of pragmatic contexts and practical norms: the case of maternal health. Health Res Policy Syst 2017;15:71-87.

16 Aniteye P, Mayhew SH. Shaping legal abortion provision in Ghana: using policy theory to understand provider-related obstacles to policy implementation. Health Res Policy Syst 2013;11:23.

17 Kapilashrami A, McPake B. Transforming governance or reinforcing hierarchies and competition: examining the public and hidden transcripts of the global fund and HIV in India. Health Policy Plan 2013;28:626-35.

18 Bohren MA, Vogel JP, Tunçalp Özge, et al. "By slapping their laps, the patient will know that you truly care for her": A qualitative study on social norms and acceptability of the mistreatment of women during childbirth in Abuja, Nigeria. SSM Popul Health 2016;2:640-55.

19 Boyd RW, Lindo EG, Weeks LD. On racism: a new standard for publishing on racial health inequities. health affairs Blog, 2020. Available: https://www.healthaffairs.org/do/

20 Kapilashrami A. What is intersectionality and what promise does it hold for advancing a rights-based sexual and reproductive health agenda? BMJ Sex Reprod Health 2020;46:4-7.

21 Landale NS, Oropesa RS. What does skin color have to do with infant health? an analysis of low birth weight among mainland and island Puerto Ricans. Soc Sci Med 2005;61:379-91.

22 Kabeer N. Social Exclusion, Poverty and Discrimination Towards an Analytical Framework. IDS Bull 2000;31:83-97.

23 Kyegombe N, Abramsky T, Devries KM, et al. The impact of Sasa!, a community mobilization intervention, on reported HIV-related risk behaviours and relationship dynamics in Kampala, Uganda. J Int AIDS Soc 2014:17:19232.

24 Balestra GL, Dasgupta J, Sandhya YK, et al. Developing political capabilities with community-based monitoring for health accountability: the case of the Mahila Swasthya Adhikar Manch. Glob Public Health 2018;13:1853-64.

25 Flores W. How can evidence bolster citizen action? learning and adapting for accountable public health in Guatemala. Washington DC: Accountability Research Center, 2018.

26 Weldon SL, Htun M. Feminist mobilisation and progressive policy change: why governments take action to combat violence against women. Gender \& development 2013;21:231-47.

27 Östlin P, Sen G, George A. Paying attention to gender and poverty in health research: content and process issues. Bull World Health Organ 2004;82:740-5.

28 Connelly M. Fatal misconception: the struggle to control world population. Cambridge: Harvard University Press, 2008.

29 Kuumba MB. Perpetuating neo-colonialism through population control: South Africa and the United States. Afr Today 1993;40:79-85. 
30 Parker R, Petchesky R, Sember R. Sex politics: reports from the front lines. sexuality policy watch 2014

31 Berer M. The Cairo 'compromise' on abortion and its consequences for making abortion safe and legal. In: Reichenbach L, Roseman $\mathrm{M}$, eds. Reproductive health and human rights: the way forward. Philadelphia: University of Pennsylvania Press, 2009: 152-64.

32 Kapur R. The Tragedy of Victimization Rhetoric: Resurrecting the "Native" Subject in International/Post-Colonial Feminist Legal Politics. Harvard Human Rights Journal 2002;15:1-28.

33 Katz AS, Hardy BJ, Firestone M, et al. Vagueness, power and public health: use of 'vulnerable 'in public health literature. Critical Public Health 2019:1-11.

34 Alsaba K, Kapilashrami A. Understanding women's experience of violence and the political economy of gender in conflict: the case of Syria. Reprod Health Matters 2016;24:5-17.

35 George AS, Amin A, de Abreu Lopes CM, et al. Structural determinants of gender inequality: why they matter for adolescent girls' sexual and reproductive health. Br Med J2020;368.
36 Davies SE, True J. When there is no justice: gendered violence and harm in post-conflict Sri Lanka. The International Journal of Human Rights 2017;21:1320-36.

37 Mialon M. An overview of the commercial determinants of health Globalization and Health 2020;16:1-7.

38 Hoover E. Environmental reproductive justice: intersections in an American Indian community impacted by environmental contamination. Environ Sociol 2018;4:8-21.

39 Eyben R, Guijt I, Roche C, et al, eds. The politics of evidence and results in international development: Playing the game to change the rules? Rugby: Practical Action Publishing, 2015.

40 Scott K, Gharai D, Sharma M, et al. Yes, no, maybe so: the importance of cognitive interviewing to enhance structured surveys on respectful maternity care in northern India. Health Policy Plan 2020;35:67-77.

41 Karris MY, Dubé K, Moore AA. What lessons it might teach us? community engagement in HIV research. Curr Opin HIV AIDS 2020;15:142-9. 